\title{
The method of observing the student's behavior in the educational environment
}

\author{
Niculeta Cristea Pleșan ${ }^{1 *}$ \\ ${ }^{1}$ University from Petrosani, University street no.20, Petrosani, Romania
}

\begin{abstract}
This paper aims to highlight the efficiency of using the method of observing student behavior in the educational environment. Observation is one of the most widely used research methods in the social sciences. The characteristics aimed at constructing the instrument were: accuracy, focus, duration of observation, awareness of the presence of the observer, the level of information of the subject. In order to observe the student's behavior in the school environment, the observation grid with standardized answers was designed on the Likert scale (scale from 1 to 10), following the degree of expression of the described behavioral manifestations.

The observation grid of the student's behavior in the school environment aims at supervising 4 dimensions (each with 5 items: observable behaviors): interest in school activities, organization of activity / punctuality in the school environment, resistance to intellectual effort, socio-affective relationships.

Following the application of the research tool, depending on the scores obtained, it is recommended the targeted psycho-pedagogical intervention at the level of the deficient dimension / behaviors, as well as the monitoring of the results through the periodic application.
\end{abstract}

\section{Observation grid of student behaviour in the school environment}

Observation is one of the most widely used methods of research in the social sciences. The characteristics of this method that we considered when the study tool was built are: accuracy, focus, duration of observation, awareness of the presence of the observer, level of information of the subject [1-7].

In order to observe the student's behaviour in the school environment, an observation grid with standardized responses on the Likert scale (scale 1 to 10) was designed, following the degree of manifestation of the described behaviors [6-10]. The advantage of "standardisation of response items introduces in addition to the non-standard observation grid the possibility of being able to compare the subjects evaluated with each other or to calculate a total score on the observed behaviour." [8-15].

The observation grid of the student's behavior in the school environment concerns the supervision of 4 dimensions, each of which is described by 5 items (observable behaviors):

*Corresponding author: nicoleta_plesan@yahoo.com 
- interest in school activities- this dimension includes the following items:

- He comes to school with pleasure.

- Shows interest in the activities carried out.

- Actively participates in the performance of school tasks.

- Demonstrates involvement in the conduct of the activity.

- Mobilizes in solving various problems.

- organization of activity/punctuality in the school environment, with items:

- It's punctual in class.

- The backpack is well organized, with all the necessary supplies for the school activity.

- The student's clothing is tidy, clean.

- Determines the stages of the school pregnancy.

- Use the time required for each step efficiently.

- resistance to intellectual effort, incorporates items:

- Sits quietly in the bank during the lesson.

- Listen carefully to the information transmitted in class.

- Responds appropriately to the teacher's requests.

- Use the available resources correctly.

- Focus on achieving the objectives set.

- socio-affective relationships with the following items:

- He is friendly with colleagues.

- Communicate appropriately in the classroom, responding politely.

- Collaborate with colleagues to carry out joint tasks.

- Value the ideas of the other members of the group.

- $\quad$ Follow the group rules (class rules).

The survey scale of student behavior in the school environment includes standardized Likert responses from 1 to 10 , with a view to their degree of behavior and their systematic notation, where 1 means absence of behavior or very little presence, while the 10 notation represents the presence of behavior to a very large extent (Table 1).

An example of using the survey grid of pupil behavior is using it within the educational partnership, "My School, the foundation of my future!", by conducting an action based on multi-disciplinary team working in the school, the objective of which is psycho-psychopsychic intervention on the target group. The target group of the project was represented by 25 students with parents who went to work abroad.

This survey of the way in which the behavior in the educational environment is expressed was completed monthly during the research period, for each student included in the project, 5 times (February - June 2016 period).

The grid aimed at monitoring the 4 dimensions described above, each of which included 5 items representing the observable behavior, scored and noted by the researcher, with the maximum score of a size being 50 .

After calculating the size score for each student participating in the study, the average was achieved for each of the 4 sizes sought. For the purpose of comparative analysis, the calculation of the averages of the observed dimensions has been carried out each month during the course of the research action.

In the following, we will present the results recorded, on each dimension, following the completion of the school pupil survey grid, results confirming the appropriateness of psychopedagogic intervention on children in difficulty, as well as the usefulness of the proposed study tool. 
Table 1. Observation grid of student behaviour in the school environment

\begin{tabular}{|c|c|c|c|c|c|c|c|c|c|c|c|}
\hline \multicolumn{12}{|c|}{$\begin{array}{c}\text { As an observer, please note as objectively as possible, on a scale from } 1 \text { to } 10 \text {, the degree of } \\
\text { pupil showing the behavior listed in the observation sheet }(1=\text { behavior not present or not present, } 10= \\
\text { behavior very present). }\end{array}$} \\
\hline \multirow{2}{*}{$\begin{array}{l}\text { Crt. } \\
\text { no. }\end{array}$} & \multirow[t]{2}{*}{ Points observed } & \multicolumn{5}{|c|}{ Score awarded } & \multirow[b]{2}{*}{6} & \multirow[b]{2}{*}{7} & \multirow[b]{2}{*}{8} & \multirow[b]{2}{*}{9} & \multirow[b]{2}{*}{10} \\
\hline & & 1 & 2 & 3 & 4 & 5 & & & & & \\
\hline 1. & $\begin{array}{l}\text { He's happy to come to } \\
\text { school. }\end{array}$ & & & & & & & & & & \\
\hline 2. & $\begin{array}{l}\text { Are of interest in the } \\
\text { activities carried out. }\end{array}$ & & & & & & & & & & \\
\hline 3. & $\begin{array}{l}\text { Actively participate } \\
\text { in school tasks. }\end{array}$ & & & & & & & & & & \\
\hline 4. & $\begin{array}{l}\text { Demonstrate } \\
\text { involvement in the } \\
\text { conduct of the } \\
\text { business. }\end{array}$ & & & & & & & & & & \\
\hline 5. & $\begin{array}{l}\text { It is mobilized to } \\
\text { solve diverse } \\
\text { problems. }\end{array}$ & & & & & & & & & & \\
\hline 6. & It's punctual to hours. & & & & & & & & & & \\
\hline 7. & $\begin{array}{l}\text { The bag is well } \\
\text { organized, with all } \\
\text { the necessary } \\
\text { requisites for school } \\
\text { activity. }\end{array}$ & & & & & & & & & & \\
\hline 8. & $\begin{array}{l}\text { The pupil's clothes } \\
\text { are neat, clean. }\end{array}$ & & & & & & & & & & \\
\hline 9. & $\begin{array}{l}\text { Sets out the steps to } \\
\text { perform the task. }\end{array}$ & & & & & & & & & & \\
\hline 10. & $\begin{array}{l}\text { Determines correctly, } \\
\text { using efficiently the } \\
\text { time needed for each } \\
\text { stage. }\end{array}$ & & & & & & & & & & \\
\hline 11. & $\begin{array}{l}\text { He is at ease in the } \\
\text { bench during the } \\
\text { class. }\end{array}$ & & & & & & & & & & \\
\hline 12. & $\begin{array}{l}\text { Listen carefully to the } \\
\text { information given in } \\
\text { hours. }\end{array}$ & & & & & & & & & & \\
\hline 13. & $\begin{array}{l}\text { Respond adequately } \\
\text { to the requests of the } \\
\text { teaching staff. }\end{array}$ & & & & & & & & & & \\
\hline 14. & $\begin{array}{l}\text { Uses available } \\
\text { resources correctly. }\end{array}$ & & & & & & & & & & \\
\hline 15. & $\begin{array}{l}\text { Focus on meeting the } \\
\text { set goals. }\end{array}$ & & & & & & & & & & \\
\hline 16. & $\begin{array}{l}\text { It's friendly with } \\
\text { colleagues. }\end{array}$ & & & & & & & & & & \\
\hline 17. & $\begin{array}{l}\text { They communicate } \\
\text { appropriately to the } \\
\text { class, responding } \\
\text { politely. }\end{array}$ & & & & & & & & & & \\
\hline 18. & $\begin{array}{l}\text { Work with colleagues } \\
\text { to perform joint tasks. }\end{array}$ & & & & & & & & & & \\
\hline 19. & $\begin{array}{l}\text { It values the ideas of } \\
\text { the other members of } \\
\text { the group. }\end{array}$ & & & & & & & & & & \\
\hline 20. & Follow group rules. & & & & & & & & & & \\
\hline
\end{tabular}




\subsection{Interest in school activities}

The results of the dimension of the school activities, the first dimension of the survey of the pupil's behavior in the school environment, are illustrated in Figure 1, the figure made on the basis of the data recorded each month during the project.

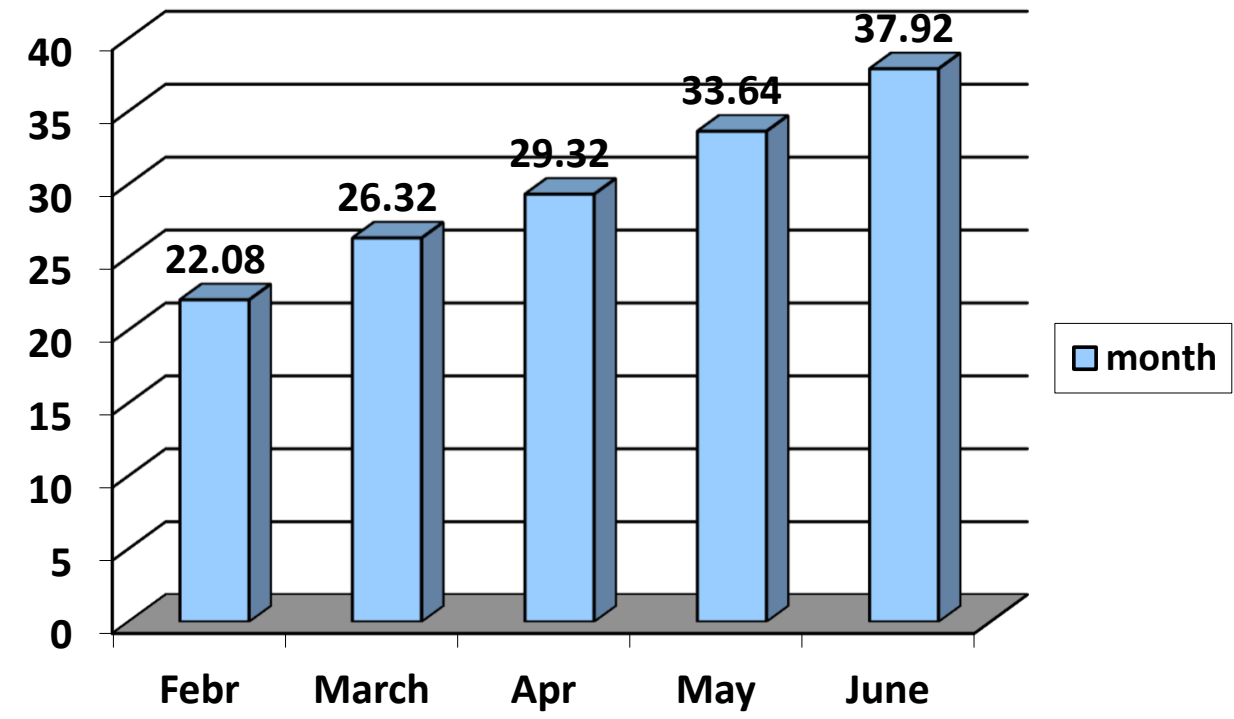

Fig.1. The averages of the size scores of interest for school activities.

As we see in Figure 1, the scores of this dimension highlight the growing interest of students participating in Action research in educational activities, coming with greater pleasure to school, participating more actively in school tasks, demonstrating better involvement and mobilization to solve various problems.

\subsection{Organization of work/punctuality in the school environment}

The results of the organization of activity/punctuality dimension in the school environment, included in the observation tool, are illustrated in Figure 2, carried out in accordance with the data collected monthly during May-June. The averages calculated for this size of the observation grid of student behavior in the school environment are slightly increasing from one month to the next, highlighting the effectiveness of monitoring participants in the educational project.

The analysis of the monthly scores averages of this dimension, as shown in Figure 2, shows an improvement in the conduct related to the organization of work/punctuality in the school environment, as a result of the psycho-educational intervention in the club for children with parents working abroad.

Students, beneficiaries of the educational project, are more punctual, less delayed at school, have better organized school bags, with the necessary educational requisites, with a clean, more orderly outfit. During school activities, it is organized better, more accurately determining the stages of tasks, making more efficient use of the time needed to carry out each stage. 


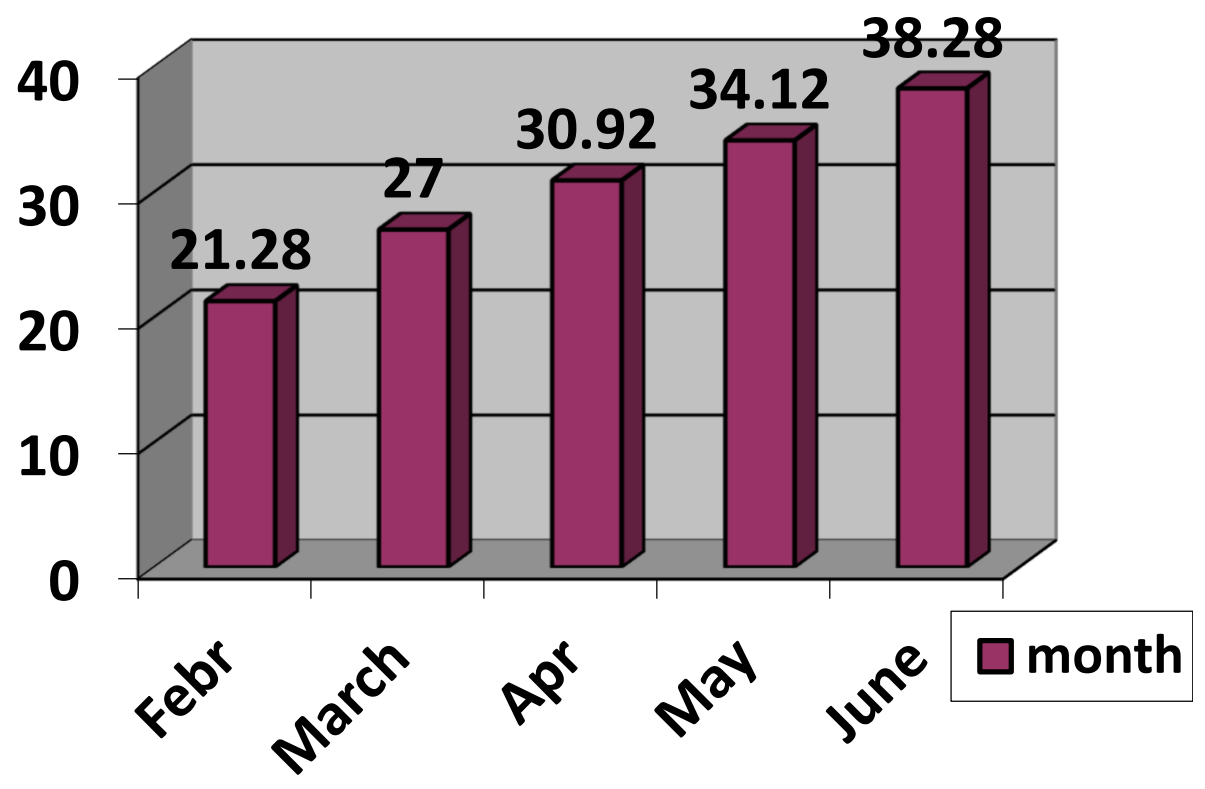

Fig.2. The average size scores organization of work/punctuality in the school environment.

\subsection{Resistance to intellectual effort}

Results of the effort-resistant dimension: Monthly scores averages can be seen in the following figure, graphical representation performed by recording the data for each aspect of this dimension: attention, focus, adequate and promising response, proper use of resources, achievement of the proposed objectives.

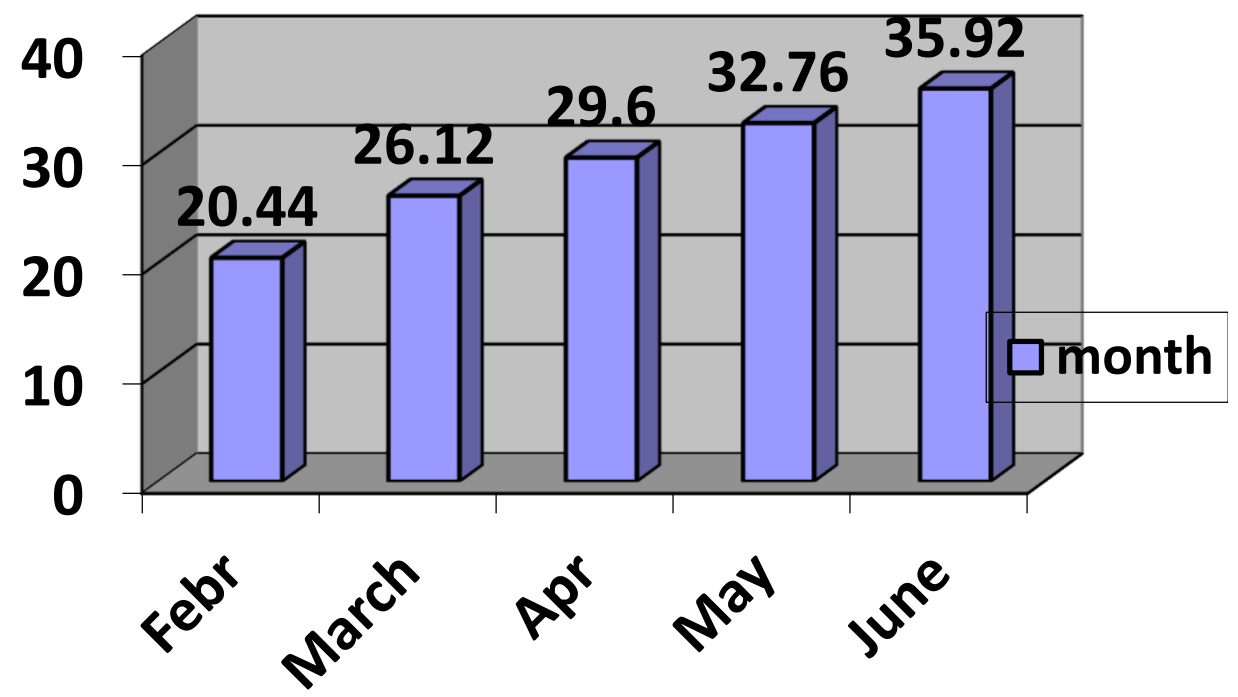

Fig.3. Intellectual effort resistant size scores averages. 


\subsection{Socio-emotional relationships}

The results of monthly scores of the socio-emotional relationship size are illustrated in Figure 4. The monitoring of socio-emotional aspects in the academic world has proved effective both in terms of pupils with parents working abroad, but may also bode well for other children in difficulty, as well as to follow how to adapt in the first years of school or at the beginning of the school year.

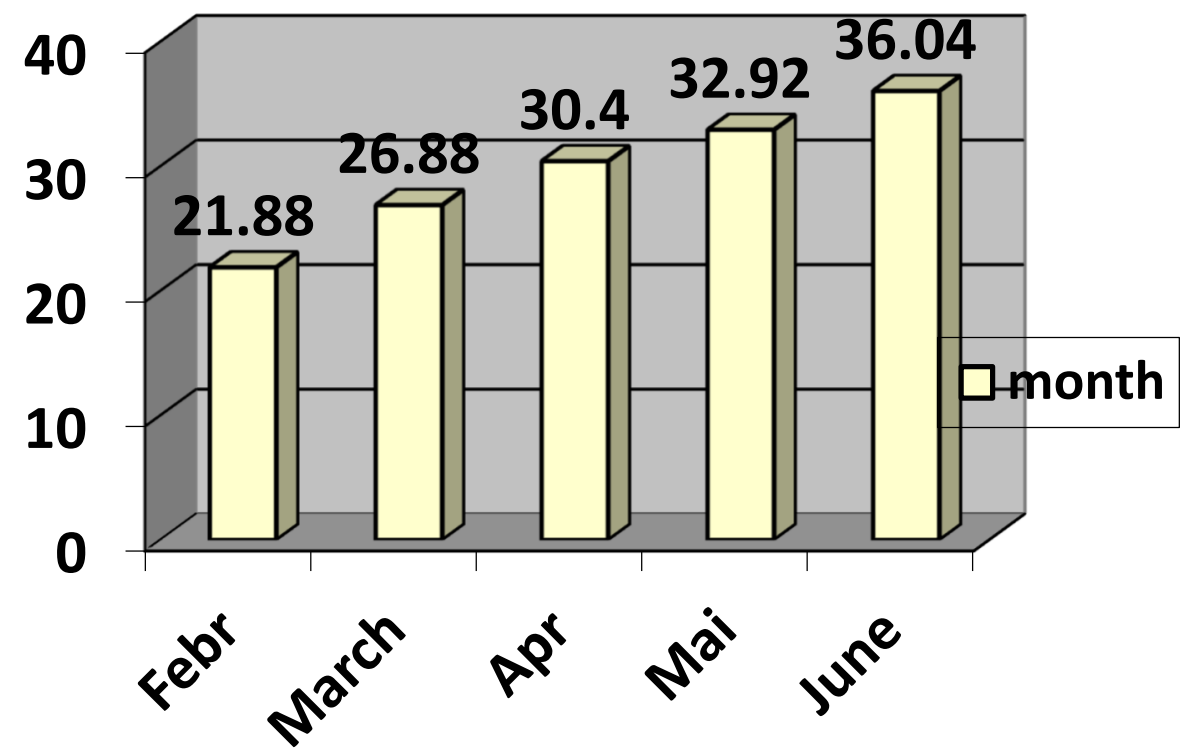

Fig.4. Averages of the socio-emotional relationship size scores.

The average monthly scores (February-June period) of the size illustrated in Figure 4 are slightly increased from one month to the next, which expresses an improvement in socioemotional relationships and the behavior of students participating in the research aimed at improving the aspects pursued: they have become more friendly, communicate and collaborate better with colleagues in order to accomplish common tasks, respond more politely and value the ideas of the other members of the group, generally respecting the rules of the class.

\section{Final discussions on the usefulness of the observation grid of student behavior in the school environment}

The present study falls within the typology of an action research in the educational field having as foundation the work in the multidisciplinary team in the school institution and the observance of the conditions of an action research:

- participation in the project was done on a voluntary basis;

- the action research was carried out within the educational partnership "My school, the foundation of my future!" Which took place during the second semester of the 2015-2016 school year.

- the activities of the educational project and implicitly, the development of the actionresearch, took place inside the General School "Teodora Lucaciu", subordinated to the Technical College "Mihai Viteazu" Vulcan, Hunedoara County; aimed at a daily practical aspect regarding the external economic migration of the parents and its influence on the 
children left at home from the point of view of the instructive-educational process, with a more relaxed vision on the scientific method;

- the stages of action research were built and applied in a spiral, having an aspect of successive sequence, revisions of the initial plan, with repeated steps of action, monitoring, evaluation, stages followed by reflection, after which the cycle resumed;

- had a role in the teacher's understanding of his own professional experience, but also its improvement;

- focused on the intervention on a small private group ( 25 students, beneficiaries of the educational partnership);

- it was a flexible and changing process, revealing to future volunteer teachers new possibilities for future action;

- the research was collaborative, conducted and evaluated by teachers who practice;

- the project had the support of various categories of professional partners: colleagues, experts, researchers;

- during the research, the data were collected, recorded, debated, evaluated and decisions were made based on the information obtained, which are observational and behavioral;

- the working tools were: The School Motivation and Learning Strategies Inventory Questionnaire (SMALSI), the observation grid of the student's behavior in the school environment; the use of these research tools was accompanied by the method of analyzing school documents;

- the judgments were based on personal knowledge of the situation, the researcher being directly involved in the development of the project.

The action research had as main objective the psycho-pedagogical intervention on students with parents working abroad, in a club of children affected by external economic migration, whose activity, based on working in a multidisciplinary team to support the development of school motivation and improvement strategies. learning. In the long run, this desideratum can be a support for the harmonious crystallization of personality traits.

\section{Conclusions}

Following the analysis and interpretation of the data of the research results, we can conclude the following:

- the participation of students affected by the external economic migration of their parents in the educational activities proposed within the children's club with their parents working abroad has resulted in improved learning strategies. Thus, following the psychoeducational intervention, progress was made by the participating students on: study strategies / skills, note-taking / listening skills, reading / comprehension strategies, writing / research skills, test strategies, techniques used on organization and time management;

- students affected by the external economic migration of their parents, who participated in the activities of the students' club with their parents working abroad, developed their motivation for learning. The analysis of the collected data highlighted the increase of students' interest in educational activities, they coming with more pleasure to school, participating more actively in school assignments, demonstrating better involvement and mobilization to solve various problems;

- psychoeducational intervention carried out by participating in the activities of the students 'club with parents working abroad, reduced the anxiety towards tests of students affected by parents' external economic migration, most having a medium level, usually of anxiety about the ways of structured examination;

- the difficulties of concentration and attention of the students affected by the external economic migration of the parents were reduced by participating in the psycho-pedagogical activities carried out within the club of the students with the parents gone to work abroad. 
Resistance to intellectual effort has also improved, with students participating in the educational project being calmer during the lesson, listening more carefully to the information provided and responding appropriately to teacher requests, making better use of available resources and focusing on achieving goals. .

- another important aspect that needs to be mentioned refers to the improvement of socioaffective relationships, the behavior of students participating in research aimed at improving the aspects followed by the observation grid: they became more friendly, communicating and collaborating better with colleagues for the accomplishment of common tasks, responding more politely and valuing the ideas of the other members of the group, respecting, in general, the rules of the class.

- the analysis of school documents highlighted the reduction of the number of unmotivated absences in the second semester compared to the number of absences accumulated in the first semester by students participating in the activities of the club set up for those whose parents work abroad, but also a slight improvement in results school.

These research findings highlight the need for changes in school activity to target students whose parents work abroad, but also the development of forms of educational support in nonformal education, such as psychoeducational intervention in a club of students affected by economic migration external parents.

\section{References}

1. R.G. Anghel; I.Horvath, Sociology of migration. Romanian theories and case studies, (Polirom Publishing House, Iași, 2009)

2. K. Chatham Stroud; C.R.Reynolds, Questionnaire for evaluating learning strategies and school motivation, (ASCR Publishing House, Cluj-Napoca, 2010)

3. M. Chraif, Experimental psychology, (University Publishing House, Bucharest, 2013)

4. I. Cerghit, Educational methods, (Polirom Publishing House, Iași, 2006)

5. L. Ciolan, Educational policies: between improvisation and professionalism, (Polirom Publishing House, Iași, 2008)

6. S. Cristea, Teaching dictionary, (Letter Publishing House, Bucharest, 2000)

7. H. Gardner, Multiple Intelligences. New horizons for theory and practice, (Sigma Publishing House, Bucharest, 2007)

8. O. Houde, Child Psychology, (Cartier Publishing House, Chisinau, 2007)

9. M. Ionescu, Instruction and education, (Garamond Publishing House, Cluj-Napoca, 2003)

10. A. Nedelcu, Research-action in education, Module 8, from the series Modules for professional development of teachers, within the project Innovation and performance in the professional development of teachers in urban areas, http://mentoraturban. pmu.ro/sites/default/files (2011)

11. N. Pleșan, The consequences of economic migration of parents for children, Proceedings of the Conference Discernible. Exercise capacity, University publishing house, Bucharest, 104-111, (2015)

12. C.Teddlie, D. Reynolds, The International Handbook of School Effectiveness Research, (Falmer Press, New York, 2000)

13. E. Stănculescu, The psychology of education from theory to practice, (University Publishing House, Bucharest, 2013)

14. P. Vianin, Strategic help for students with school difficulties, (ASCR Publishing House, ClujNapoca, 2011)

15. E. Vrăsmaş, Methodology on combating discrimination and school exclusion of children and young people with special educational needs through collaboration and multidisciplinary intervention, RENINCO-FDP-FDRS, Bucharest (2016) 